\title{
Case Report: Pseudomonas can take a toll on a patient
}

\section{[version 1; peer review: 2 approved]}

\author{
David K. Buchbinder(D1, Jasjit Singh², Tuan Dao33, Aaron Sassoon4, \\ Antonio Arrieta ${ }^{2}$ \\ ${ }^{1}$ Department of Hematology, CHOC Chidren's Hospital, Orange, CA, 92868, USA \\ 2Department of Infectious Disease, CHOC Children's Hospital, Orange, CA, 92868, USA \\ ${ }^{3}$ Department of Radiology, CHOC Children's Hospital, Orange, CA, 92868, USA \\ ${ }^{4}$ Department of Pathology, CHOC Children's Hospital, Orange, CA, 92868, USA
}

V1 First published: $01 \mathrm{Jul} 2021,10: 526$

https://doi.org/10.12688/f1000research.53424.1

Latest published: $21 \mathrm{Sep}$ 2021, 10:526

https://doi.org/10.12688/f1000research.53424.2

\section{Abstract}

Pseudomonas aeruginosa ( $P$. aeruginosa) is an aerobic Gramnegative bacterium that is implicated in the development of severe systemic infections among pediatric patients. It is identified in hospitalized chronically ill pediatric patients in association with genitourinary, respiratory tract, and skin or soft tissue infections as well as severe and life-threating infection including sepsis. A variety of immunologic mechanisms play a vital role in the host defense mechanisms against invasive infections with $P$. aeruginosa. Rarely, specific inborn errors of immune function are implicated in deficiencies that predispose to invasive infections with $P$. aeruginosa. Innate immune function including germ-line encoded pattern recognition receptors such as toll-like receptors (TLRs) and their downstream signaling is vital in the host defense against $P$. aeruginosa through the generation of antimicrobial peptides, cytokines/chemokines, and shaping of adaptive immune responses. Herein, we describe a previously healthy two-year-old female with an invasive skin, soft tissue, and central nervous system infection secondary to $P$. aeruginosa. The invasive nature of this infection prompted a careful evaluation for an inborn error of immunity. Decreased cytokine response to agonists of TLRs was documented. Targeted sequencing of interleukin-1 receptor-associated kinase (IRAK)-4 documented a homozygous deletion of exons 8-13 consistent with IRAK-4 deficiency. This report provides a vital educative message in the existing scientific literature by underscoring the importance of considering inborn errors of immunity in all patients with severe $P$. aeruginosa infections. Functional assessments of immune function often in combination with sequencing can accurately assign a diagnosis in a timely fashion allowing for definitive treatment and the use of necessary supportive care.

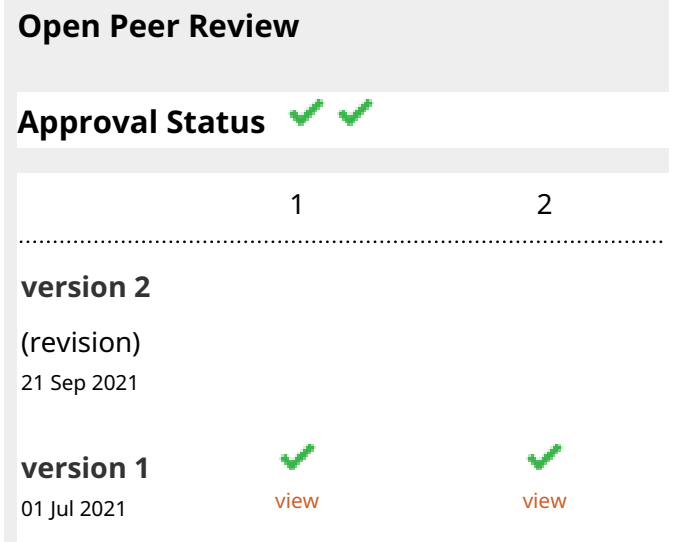

1. David Hagin, Tel Aviv University, Tel Aviv, Israel

\section{Shanmuganathan Chandrakasan (D),}

Emory University, Atlanta, USA

Any reports and responses or comments on the article can be found at the end of the article. 


\section{Keywords}

innate immunity, toll like receptors, interleukin-1 receptor-associated

kinase-4, case report

Corresponding author: David K. Buchbinder (dbuchbinder@choc.org)

Author roles: Buchbinder DK: Conceptualization, Writing - Original Draft Preparation, Writing - Review \& Editing; Singh J:

Conceptualization, Writing - Original Draft Preparation, Writing - Review \& Editing; Dao T: Writing - Original Draft Preparation, Writing -

Review \& Editing; Sassoon A: Writing - Original Draft Preparation, Writing - Review \& Editing; Arrieta A: Writing - Original Draft

Preparation, Writing - Review \& Editing

Competing interests: No competing interests were disclosed.

Grant information: The author(s) declared that no grants were involved in supporting this work.

Copyright: @ 2021 Buchbinder DK et al. This is an open access article distributed under the terms of the Creative Commons Attribution License, which permits unrestricted use, distribution, and reproduction in any medium, provided the original work is properly cited.

How to cite this article: Buchbinder DK, Singh J, Dao T et al. Case Report: Pseudomonas can take a toll on a patient [version 1; peer review: 2 approved] F1000Research 2021, 10:526 https://doi.org/10.12688/f1000research.53424.1

First published: 01 Jul 2021, 10:526 https://doi.org/10.12688/f1000research.53424.1 


\section{Introduction}

Pseudomonas aeruginosa (P. aeruginosa) is an opportunistic aerobic Gram-negative bacterial pathogen associated with a variety of genitourinary (UTI), pulmonary as well as skin and soft tissue infections (SSTI) in hospitalized pediatric patients often in association with significant morbidity. ${ }^{1}$ Rarely, $P$. aeruginosa can be associated with severe and lifethreatening infections among children without previously recognized associated risk factors. ${ }^{2}$ In these cases, it is vital to consider the possibility of an underlying inborn error of immunity. Invasive $P$. aeruginosa infections have been described in the setting of inborn errors of immunity including antibody deficiencies (agammaglobulinemia) Bruton (BTK), combined immunodeficiency disorders (severe combined immunodeficiency, ataxia telangiectasia), defects of phagocytes (chronic granulomatous disease, leukocyte adhesion deficiency), defects in actin-polymerization (Wiskott-Aldrich syndrome, MKL1-deficiency), chronic neutropenia and innate immunity including defects in canonical NFKB-signaling (e.g., NEMO/NFKBIA) as well as those that impair the downstream signaling of toll-like receptors (TLRs), such as defects in interleukin-1 receptor-associated kinase (IRAK)-4 and myeloid differentiation factor 88 (MyD88). ${ }^{2,3}$ We describe the presence of an invasive soft tissue and central nervous system infection with $P$. aeruginosa in a previously healthy two-year-old female which prompted evaluation for an inborn error of immunity.

\section{Case report}

A previously healthy two-year-old Hispanic female was evaluated for left hip and knee pain associated with a fever and a refusal to ambulate. She had been given cephalexin for presumed insect bites on her back and legs. Her past medical history was non-contributory. She was fully immunized. Her family history was negative for consanguinity and inborn errors of immunity. She was afebrile and her physical examination demonstrated a $3 \mathrm{~cm}$ circular erythematous lesion on mid left back which was non-indurated. Her left knee was minimally swollen, warm to touch, and non-erythematous. Her hips and knees remained in flexion with demonstrated resistance to knee extension. A nodular $1.5 \mathrm{~cm}$ mass in her popliteal fossa was also documented with tenderness upon palpation and she was unable to walk. Her laboratory investigation demonstrated a white blood cell count of $17.2 \times 10^{3} / \mathrm{uL}$ (normal range: 3.9-13.7), Hgb $10.4 \mathrm{~g} / \mathrm{dL}$ (normal range:10.215.4), platelets $319 \times 10^{3}$ (normal range: $150-450$ ), $64 \%$ neutrophils (normal range: $25-72$ ), $26 \%$ lymphocytes (normal range: $24-71), 9 \%$ monocytes (normal range: $0-14), 0.6 \%$ eosinophils (normal range: $2-10$ ), $0.3 \%$ basophils (normal range: 0-2), erythrocyte sedimentation rate (ESR) $126 \mathrm{~mm} / \mathrm{hr}$ (normal range: 0-20), and C-reactive protein (CRP) 68.8 $\mathrm{mg} / \mathrm{L}$ (normal range: 0-10). A blood culture was negative. Magnetic resonance (MR) imaging of her lower extremity

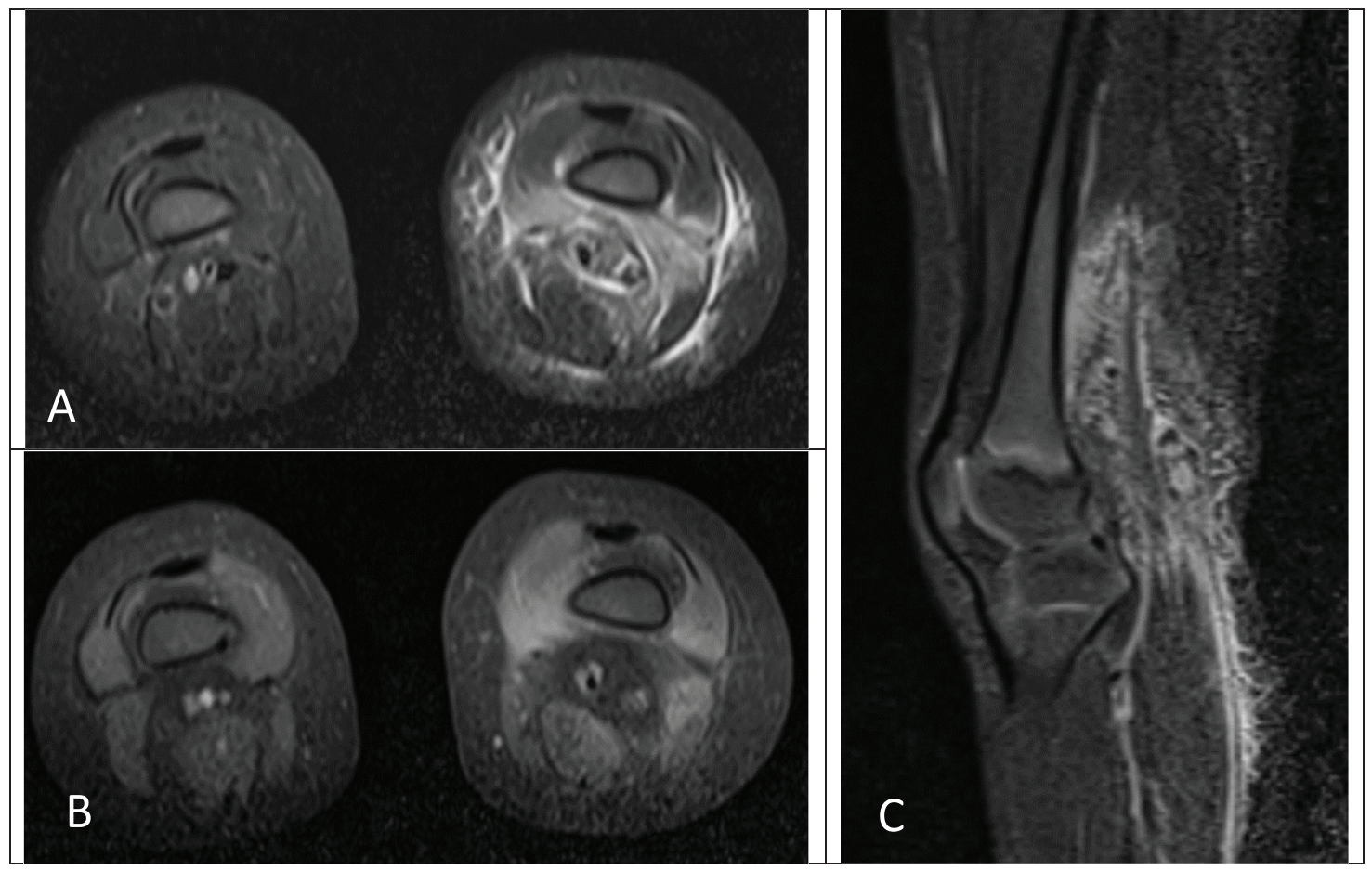

Figure 1. Axial (A) and sagittal (C) Short-TI Inversion Recovery (STIR) magnetic resonance imaging (MRI) images of the bilateral lower extremities demonstrate edematous signal involving the left lower extremity vastus medialis, vastus intermedius, soft tissues of the popliteal fossa, and overlying subcutaneous soft tissues. Axial fat-saturated T1-weighted postcontrast MRI of the bilateral lower extremities (B) demonstrates associated enhancement of the vastus medialis, vastus intermedius, and soft tissues of the popliteal fossa. Findings are compatible with myositis with overlying cellulitis. 
demonstrated myositis and fasciitis involving the soft tissues of the distal left thigh, but no abscess (Figure 1A-C). Likely pathogens included methicillin sensitive Staphylococcus aureus, methicillin resistant Staphylococcus aureus, and group A Streptococcus.

Empiric antibiotic therapy began with vancomycin $(60 \mathrm{mg} / \mathrm{kg} /$ day intravenously divided every 6 hours for 3 days $)$ and ceftriaxone $(75 \mathrm{mg} / \mathrm{kg} /$ day intravenously every 24 hours for 3 days) which was then transitioned to cefazolin $(100 \mathrm{mg} / \mathrm{kg} /$ day intravenously divided every 8 hours for 7 days), clindamycin ( $30 \mathrm{mg} / \mathrm{kg} /$ day intravenously divided every 8 hours for 7 days), amoxicillin-clavulanate $(50 \mathrm{mg} / \mathrm{kg} /$ day orally divided every 12 hours for 4 days $)$, and then to linezolid $(30 \mathrm{mg} / \mathrm{kg} /$ day intravenously divided every 8 hours for 6 days) due to a lack of clinical and laboratory improvement. A lesion on her back was biopsied and demonstrated acute suppurative panniculitis and suppurative necrosis (Figure 2). Cultures were obtained with growth of $P$. aeruginos $a$ and a 3 -week course of cefepime $(150 \mathrm{mg} / \mathrm{kg} / \mathrm{day}$ intravenously divided every 8 hours) for SSTI was completed. Clinical and laboratory improvement occurred as demonstrated by an ESR $57 \mathrm{~mm} / \mathrm{hr}$ (normal range: 0-20) and CRP $<5 \mathrm{mg} / \mathrm{L}$ (normal range: $0-10$ ). The patient was discharged while awaiting results of a workup for an inborn error of immunity.

She then returned approximately 3 weeks later with malaise, an inability to stand upright, irritability, and pain on palpation of her back as well as a refusal to ambulate. On re-admission she was afebrile, and her laboratory investigation demonstrated an ESR $89 \mathrm{~mm} / \mathrm{hr}$ (normal range: 0-20), and CRP $<5 \mathrm{mg} / \mathrm{L}$ (normal range: 0-10). MR imaging of her spine demonstrated enhancement of T9-T11 with an epidural abscess (Figure 3A-B). A culture was obtained by computed tomography (CT)-guided needle aspiration and empiric therapy with meropenem $(120 \mathrm{mg} / \mathrm{kg} /$ day intravenously divided every 8 hours for 2 days) was begun. Growth of $P$. aeruginosa was documented and a 6-week course of cefepime $(150 \mathrm{mg} / \mathrm{kg} /$ day intravenously divided every 8 hours) was completed. Clinical improvement occurred; however, her laboratory investigation demonstrated an ESR $80 \mathrm{~mm} / \mathrm{hr}$ (normal range: 0-20) and CRP $<5 \mathrm{mg} / \mathrm{L}$ (normal range: 0-10) at the completion of therapy.

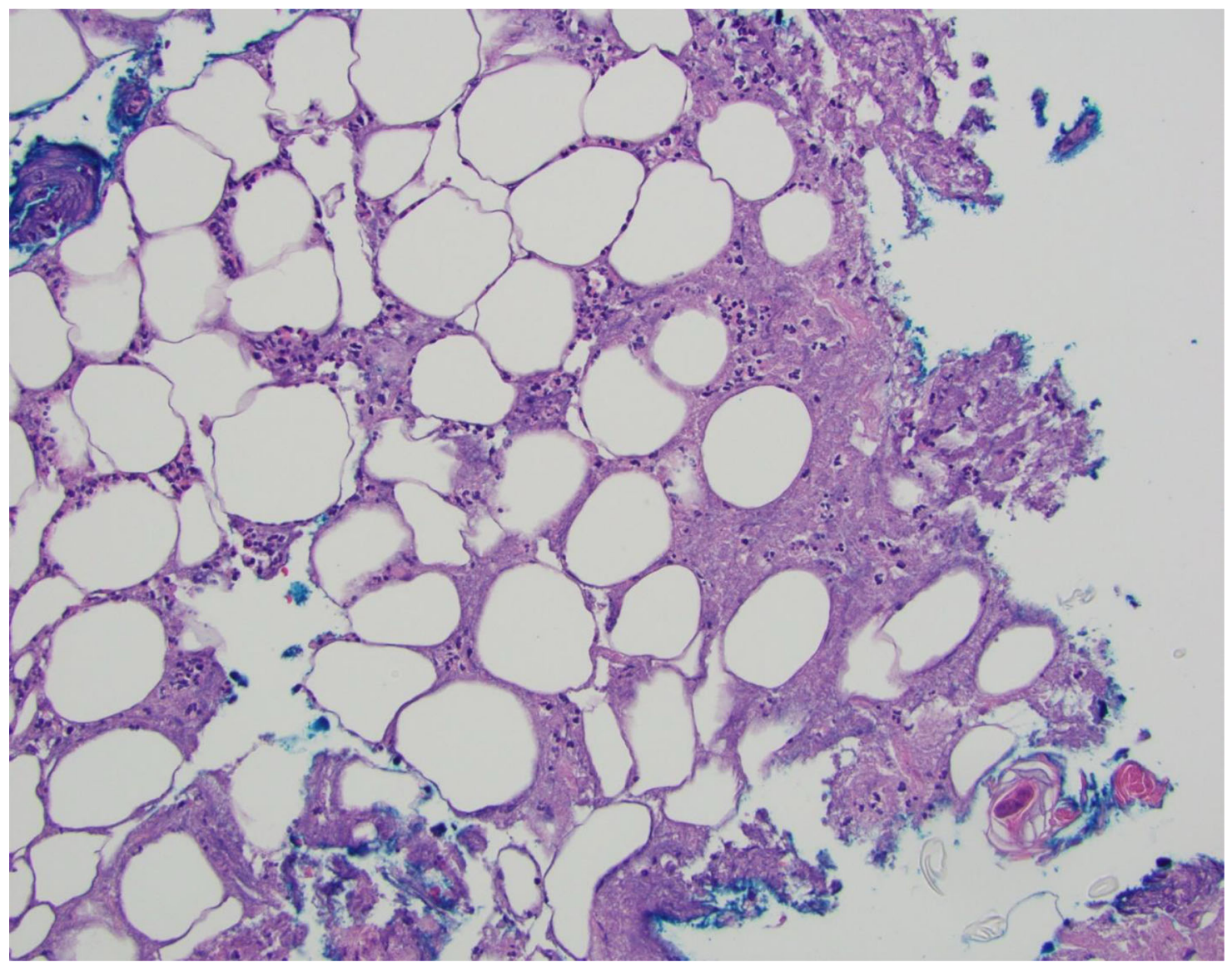

Figure 2. Skin punch biopsy demonstrates acute suppurative panniculitis with suppurative necrosis $(20 \times$, Hematoxylin and Eosin). 


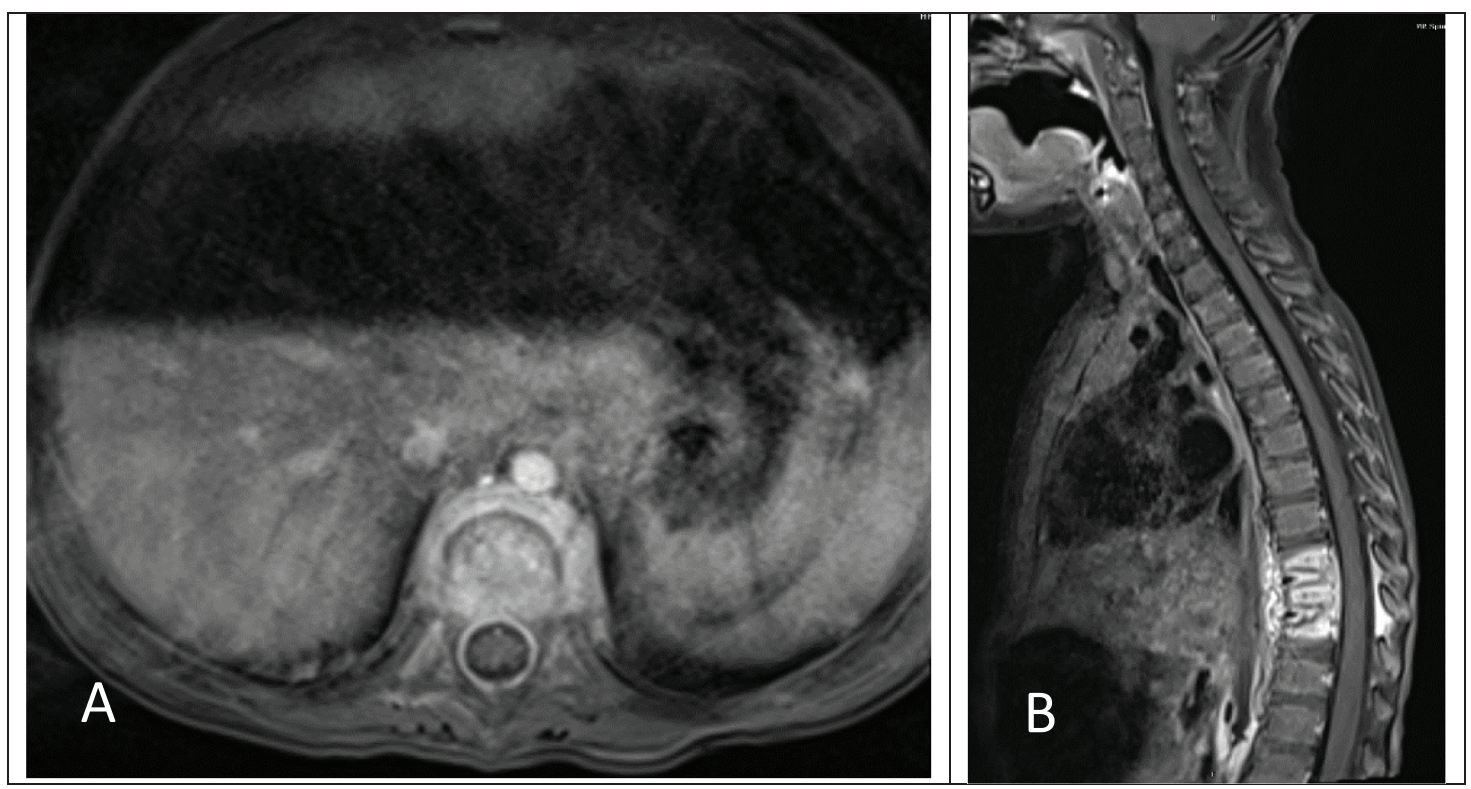

Figure 3. Axial (A) and sagittal (B) fat-saturated volumetric interpolated breath-hold examination (VIBE) postcontrast magnetic resonance imagery (MRI) images of the thoracic spine demonstrate multilevel thoracic osteomyelitis and discitis with associated epidural and paravertebral abscesses.

Secondary to the invasive nature of her P. aeruginosa infection, evaluation for an inborn error of immunity was completed. A normal neutrophil oxidative burst was noted. Additional laboratory assessments included a serum $\operatorname{IgG~} 1331 \mathrm{mg} / \mathrm{dL}$ (normal range: 407-1009), IgA 85 mg/dL (normal range: 22-220), an elevated IgM $362 \mathrm{mg} / \mathrm{dL}$ (normal range: 43-163), and a IgE $3.8 \mathrm{kU} / \mathrm{L}$ (normal range: <97). Antibody responses documented a non-protective Haemophilus influenza type b antibody titer $(0.30 \mathrm{mcg} / \mathrm{L})$, a tetanus antibody titer which was protective $(0.21 \mathrm{IU} / \mathrm{mL})$, and pneumococcal titers which were protective $(>1.3 \mathrm{mcg} / \mathrm{L})$ for nearly all serotypes covered by Prevnar 13. Lymphocyte immunophenotyping demonstrated a $\mathrm{CD} 3+$ count of 1340/ uL (normal range: 1484-5327), CD4+ count of 633 / uL (normal range: 733-3181), CD8+ count of 628/uL (normal range: 370-2555), CD19+ count of 493/uL (normal range: 370-2306), CD16/56+ count of 109/uL (normal range: 43-526). Decreased cytokine response to TLR agonists were documented (Figure 4). Targeted sequencing of IRAK-4 and MyD88 was performed. A homozygous deletion of exons 8-13 was documented in IRAK-4 consistent with a diagnosis of IRAK-4 deficiency.

Following the diagnosis of IRAK-4 deficiency she was start prophylaxis with intravenous immunoglobulin $(0.5 \mathrm{~g} / \mathrm{kg} /$ dose intravenously every 4 weeks) as well as amoxicillin ( $250 \mathrm{mg}$ orally each day). From her diagnosis at 2 years of age until 4 years of age she continued to experience infrequent infectious complications including a urinary tract infection (Escherichia coli), left knee swelling in association with a abscess (methicillin-susceptible Staphylococcus aureus), and a single admission for fever, cough, and post-tussive emesis. She is now 6 years of age and doing well without any recent infectious complications. She remains compliant with her prophylaxis therapy with intravenous immunoglobulin therapy and amoxicillin which she has tolerated without complications.

\section{Discussion}

Detection of lipopolysaccharide and flagellin by TLRs results in the elaboration of pro-inflammatory cytokines. ${ }^{3}$ TLRs possess an intracellular domain known as the Toll-IL-1R domain (TIR). Upon activation of TLRs, the recruitment of TIR-containing cytosolic adaptors such as MyD88 occurs. The adaptor MyD88 then recruits cytosolic kinases, including the IRAK complex. The IRAK complex includes two kinases including IRAK-4 and two non-catalytic subunits. This results in the activation of downstream effectors including nuclear factor $\kappa \mathrm{B}(\mathrm{NF}-\kappa \mathrm{B})$ and mitogen-activated protein kinases which support the synthesis of pro-inflammatory cytokines and chemokines, such as IL-1 $\beta,-6,-8$, and -12 and tumor necrosis factor alpha.

IRAK-4 deficiency is an autosomal recessive disorder which requires that affected patients have homozygous or compound heterozygous mutations in the IRAK-4. ${ }^{4,5}$ IRAK-4 deficient patients typically have normal basic immunological evaluations. ${ }^{4,5}$ Importantly, inflammatory responses are markedly blunted as demonstrated by the severe and lifethreatening invasive bacterial infection with $P$. aeruginosa in our patient accompanied by an absence of CRP elevation. 


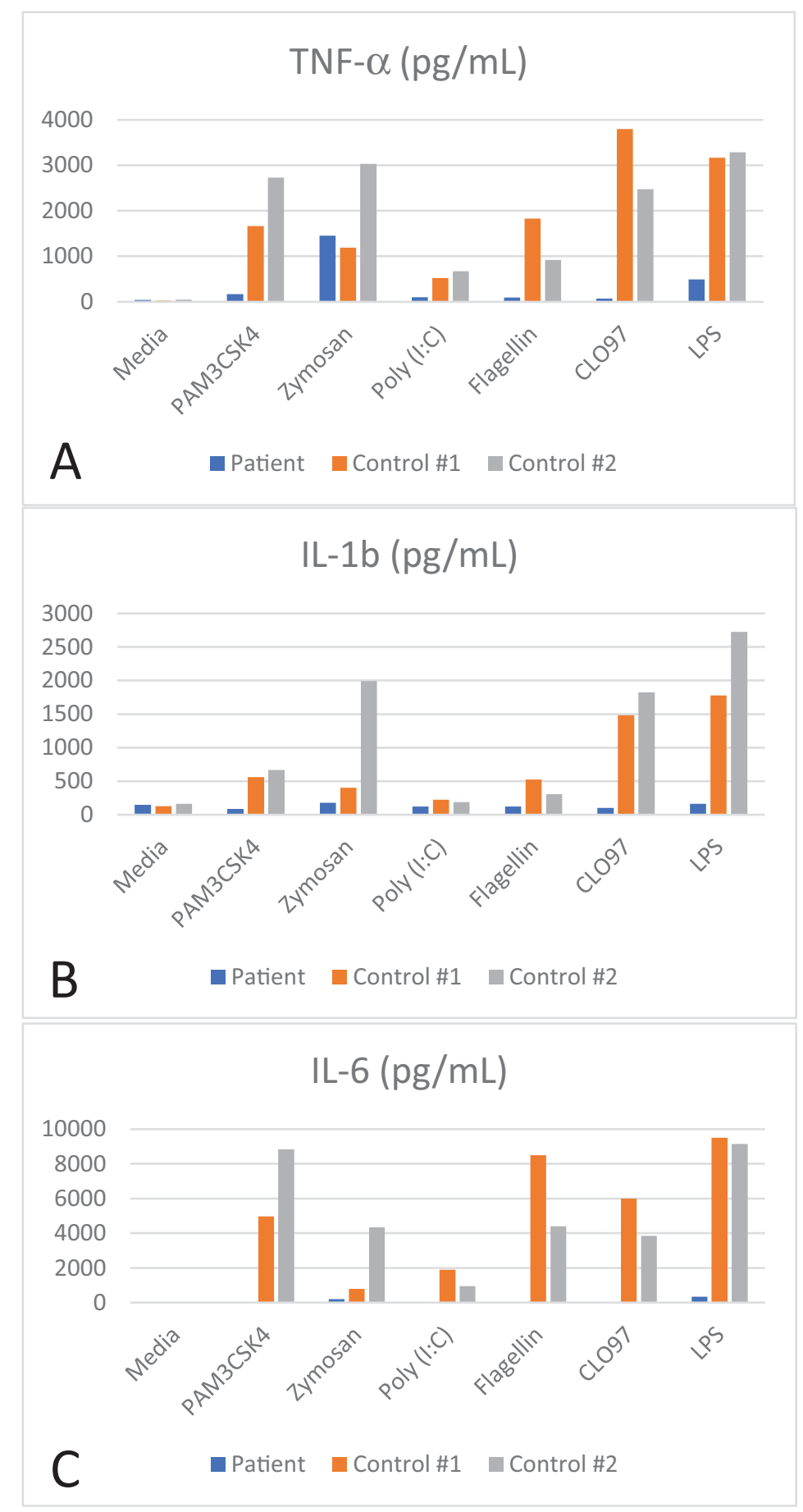

Figure 4. Decreased cytokine response to toll-like receptor (TLR) agonists: A) TNF alpha, B) IL-1b, and C) IL-6 was measured following peripheral blood mononuclear cell (PBMC) stimulation with PAM3CSK4 (TLR2 and TLR1), zymosan (TLR2 and TLR6), Poly (I:C) (TLR3), flagellin (TLR 5), CL097 (TLR7 and TLR8), and LPS (TLR4).

In these patients, CRP concentrations can be strikingly misleading as IRAK-4 deficient patients demonstrate impairment in the ability to increase CRP concentrations and to mount fever responses.

Among IRAK-4 deficient patients with invasive bacterial infection, S. pneumoniae is the most frequently ( 50\% of episodes) implicated organism. ${ }^{5}$ S. aureus and P. aeruginosa are less frequently ( $20 \%$ of episodes) implicated organisms. ${ }^{5}$ Patients with IRAK-4 deficiency may also experience a variety of minor non-invasive bacterial infections 
such as upper respiratory tract infections (otitis, sinusitis, pharyngitis) as well as SSTI (furunculosis, folliculitis cellulitis). ${ }^{5}$ Once again, the most frequently implicated organisms in these non-invasive bacterial infections among IRAK-4 deficient patients are $S$. pneumoniae, $S$. aureus, and $P$. aeruginosa.

Careful institution of aggressive supportive care measures is necessary for IRAK-4 deficient patients. Vaccines should include conjugated and nonconjugated vaccines for S. pneumoniae and N. meningitidis. Haemophilus influenzae type b conjugated vaccine should also be provided. Lifelong antibiotic prophylaxis with cotrimoxazole in combination with penicillin should be administered. Prophylaxis with intravenous or subcutaneous IgG should also be provided. Empiric parenteral antibiotic therapy against $S$. pneumoniae, $S$. aureus, and $P$. aeruginosa is critical whenever an infection is suspected or if the patient develops a fever. Inflammatory markers such as CRP should be considered unreliable. Importantly, patients may die from invasive bacterial infection despite prophylaxis even in the absence of fever or laboratory evidence of inflammation.

Although the occurrence of invasive $P$. aeruginosa infections in IRAK-4 deficiency is not novel, there is a vital and important educative message that bears repeating. Astute clinical judgment is necessary in the evaluation of patients with a potential inborn error of immunity. Clinical findings such as severe infections with $P$. aeruginosa should support the consideration of inborn errors of immunity including IRAK-4 deficiency.

\section{Data availability}

All data underlying the results are available as part of the article and no additional source data are required.

\section{Consent}

Written informed consent for publication of their clinical details and/or clinical images was obtained from the parent of the patient.

1. Klockgether J, Tümmler B: Recent advances in understanding Pseudomonas aeruginosa as a pathogen. f1000Res. 2017 Jul 28; 6 : 1261.

PubMed Abstract | Publisher Full Text | Free Full Text

2. Asgari S, McLaren PJ, Peake J, et al.: Exome Sequencing Reveals Primary Immunodeficiencies in Children with CommunityAcquired Pseudomonas aeruginosa Sepsis. Front Immunol. 2016 Sep 20; 7: 357.

PubMed Abstract | Publisher Full Text | Free Full Text

3. Casanova JL, Abel L, Quintana-Murci L: Human TLRs and IL-1Rs in Host Defense: Natural Insights from Evolutionary,
Epidemiological, and Clinical Genetics. Annu Rev Immunol. 2011; 29: 447-491.

PubMed Abstract | Publisher Full Text

4. Picard C, Puel A, Bonnet M, et al.: Pyogenic bacterial infections in humans with IRAK-4 deficiency. Science. 2003 Mar 28; 299(5615): 2076-2079.

PubMed Abstract | Publisher Full Text

5. Picard C, von Bernuth $\mathrm{H}$, Ghandil $\mathrm{P}$, et al.: Clinical features and outcome of patients with IRAK-4 and MyD88 deficiency. Medicine (Baltimore). 2010 Nov; 89(6): 403-25.

PubMed Abstract | Publisher Full Text | Free Full Text 


\section{Open Peer Review}

\section{Current Peer Review Status:}

\section{Version 1}

Reviewer Report 29 July 2021

https://doi.org/10.5256/f1000research.56805.r88939

(C) 2021 Chandrakasan S. This is an open access peer review report distributed under the terms of the Creative Commons Attribution License, which permits unrestricted use, distribution, and reproduction in any medium, provided the original work is properly cited.

\section{Shanmuganathan Chandrakasan}

Division of Bone Marrow Transplant, Aflac Cancer and Blood Disorders Center, Children's Healthcare of Atlanta, Emory University, Atlanta, GA, USA

Very well-written case report of a child with IRAK4 deficiency. I have no major comments, few minor comments include:

Briefly discuss the role of CD62L shedding assay as another screening test. ${ }^{1}$

Explain briefly why there is a need for Ig replacement in a disorder that is mainly myeloid lineage being affected-it might be of interest to the readers

A line on long term prognosis might be helpful- the risk of invasive infection tend to improve with age

\section{References}

1. von Bernuth $\mathrm{H}$, Ku CL, Rodriguez-Gallego C, Zhang S, et al.: A fast procedure for the detection of defects in Toll-like receptor signaling.Pediatrics. 2006; 118 (6): 2498-503 PubMed Abstract | Publisher Full Text

Is the background of the case's history and progression described in sufficient detail? Yes

Are enough details provided of any physical examination and diagnostic tests, treatment given and outcomes?

Yes

Is sufficient discussion included of the importance of the findings and their relevance to future understanding of disease processes, diagnosis or treatment? 


\section{Is the case presented with sufficient detail to be useful for other practitioners? \\ Yes}

Competing Interests: No competing interests were disclosed.

Reviewer Expertise: Immunobiology of Immune dysregulation disorders; HSCT and gene therapy for immune defects

\section{I confirm that I have read this submission and believe that I have an appropriate level of expertise to confirm that it is of an acceptable scientific standard.}

Author Response 18 Aug 2021

David K. Buchbinder, CHOC Chidren's Hospital, Orange, USA

Reviewer \#2:

Comment \#1:

Briefly discuss the role of CD62L shedding assay as another screening test.

Response \#1:

Thank you for this excellent and important suggestion. Additional discussion regarding the role of the CD62L shedding assay as a potential screening test has been added. The suggested reference has also been added.

von Bernuth $\mathrm{H}$, $\mathrm{Ku} \mathrm{CL}$, Rodriguez-Gallego $\mathrm{C}$, Zhang S, et al.: A fast procedure for the detection of defects in Toll-like receptor signaling.Pediatrics. 2006; 118 (6): 2498-503.

\section{Comment \#2:}

Explain briefly why there is a need for Ig replacement in a disorder that is mainly myeloid lineage being affected- it might be of interest to the readers

Response \#2:

Thank you for this suggestion. Additional discussion focusing on explaining why immunoglobulin prophylaxis has a role in IRAK4 deficiency has been added.

\section{Comment \#3:}

A line on long term prognosis might be helpful- the risk of invasive infection tend to improve with age

Response \#3:

We apologize for this omission and agree that it is important to comment on the long-term 
prognosis of patients with IRAK4 deficiency.

Competing Interests: I have no competing interests to disclose.

Reviewer Report 05 July 2021

https://doi.org/10.5256/f1000research.56805.r88936

(C) 2021 Hagin D. This is an open access peer review report distributed under the terms of the Creative Commons Attribution License, which permits unrestricted use, distribution, and reproduction in any medium, provided the original work is properly cited.

\section{David Hagin}

Sackler Faculty of Medicine, Tel Aviv University, Tel Aviv, Israel

I had a pleasure reading this case report. The authors nicely describe a rare case of IRAK-4 deficiency in a female patient with invasive pseudomonal infection.

The case report highlights several important issues. First, and most important, unusual and/or severe presentation should trigger further evaluation for possible underlying inborn errors of immunity (IEI). In this case, invasive infection and failure to respond to antibiotics raised this concern.

Next, the case report highlights additional important laboratory findings, such as normal CRP levels in the presence of severe infection. In that regard, this case report shows that 'normal' CRP should not always be considered a reassuring sign, but rather the opposite, and in some cases could suggest a failure to mount a required inflammatory response.

Finally, the case report describes a very elegant stepwise work-up approach, starting with identifying 'clinical clues' (such as normal CRP), followed by ordering the correct diagnostic assay, and finally performing targeted sequencing of a single candidate gene (sadly, not that common anymore).

There are several minor points I would like to suggest:

1. Decreased cytokine response to TLR agonists: Was that performed by a commercial lab? If so, I think I would mention it so readers would know that it can be ordered. Also, which cells were used (fibroblasts/PBMCs)?

2. Were the authors able to test for LPS-induced CD62L shedding in neutrophils?

3. I don't know if the patient has siblings, but perhaps the Discussion should include a recommendation to screen other family members for the same pathogenic variants.

Is the background of the case's history and progression described in sufficient detail? 
Are enough details provided of any physical examination and diagnostic tests, treatment given and outcomes?

Yes

Is sufficient discussion included of the importance of the findings and their relevance to future understanding of disease processes, diagnosis or treatment?

Yes

Is the case presented with sufficient detail to be useful for other practitioners?

Yes

Competing Interests: No competing interests were disclosed.

Reviewer Expertise: Inborn Errors of Immunity/Primary Immunodeficiency Disorders

I confirm that I have read this submission and believe that I have an appropriate level of expertise to confirm that it is of an acceptable scientific standard.

Author Response 18 Aug 2021

David K. Buchbinder, CHOC Chidren's Hospital, Orange, USA

Reviewer \#1:

Comment \#1:

Decreased cytokine response to TLR agonists: Was that performed by a commercial lab? If so, I think I would mention it so readers would know that it can be ordered. Also, which cells were used (fibroblasts/PBMCs)?

Response \#1:

Thank you for this comment. The cytokine response to TLR agonists was performed by a commercial lab. We agree that this is important to point out for readers. Moreover, peripheral blood mononuclear cells were utilized for testing. This was also pointed out to help other readers/clinicians that may be facing similar clinical situations.

Comment \#2:

Were the authors able to test for LPS-induced CD62L shedding in neutrophils?

Response \#2:

We did not test for LPS-induced CD62L shedding in neutrophils. As suggested by Reviewer $\# 2$, additional discussion regarding the role of the CD62L shedding assay as a potential 
screening test has been added.

\section{Comment \#3:}

I don't know if the patient has siblings, but perhaps the Discussion should include a recommendation to screen other family members for the same pathogenic variants.

Response \#3:

The patient does not have any siblings, but we agree that this is an important point to make from a clinical perspective. Additional discussion regarding the importance of screening other family members for the same pathogenic variants has been added.

Competing Interests: I have no competing interests.

The benefits of publishing with F1000Research:

- Your article is published within days, with no editorial bias

- You can publish traditional articles, null/negative results, case reports, data notes and more

- The peer review process is transparent and collaborative

- Your article is indexed in PubMed after passing peer review

- Dedicated customer support at every stage

For pre-submission enquiries, contact research@f1000.com 